\title{
Lung Hydatid Cyst in Children
}

\author{
Arturo L. Delgado ${ }^{1}$, Emma Muendo Loko ${ }^{2}$ and Adupa Dhaffala ${ }^{2}$ \\ 1. Paediatric Surgery, Nelson Mandela Academic Hospital, Walter Sisulu University, Eastern Cape, South Africa \\ 2. Department of Surgery, Nelson Mandela Academic Hospital, Walter Sisulu University, Eastern Cape, South Africa
}

\begin{abstract}
Hydatid infestation of the lung can be primary or secondary. Cystic echinococcosis (CE) is regarded as endemic in Sub-Saharan Africa, however, for most countries only scarce data, if any, exist. This is a retrospective analysis of children below 13 years with lung hydatid cyst admitted in the paediatric surgical ward at NMAH (Nelson Mandela Academic Hospital) in Eastern Cape, South Africa. The study period was from September 2015 to September 2017. The variables studied were age, sex, imagen findings, cysts sizes, treatment and complications. Prevalence and behaviour of lung hydatic cyst in our children were found out. There were 12 children studied, 8 females and 4 males. The age ranges from 5 to 10 years. The $50 \%$ of the children were to 10 years. The left lung was more affected, 7 patients constituting $58.3 \%$, bilateral disease was seen in 3 patients. Treatment was surgical: punction, aspiration, injection and reaspiration (PAIR), removal of germinal layer, and partial capitonnage on a drain tube in 8 children (67\%). A pharmacological treatment was offered to 4 patients. There was rupture of a cyst into the pleural space before surgery. Postoperatively 7 children developed broncho-pleural fistula. There was no mortality in this study. Hydatid cyst of the lung was most frequent on the left side. The surgical treatment performed was PAIR mostly in cysts more than $6 \mathrm{~cm}$ or with complications. Conservative treatment is an option in some cases.
\end{abstract}

Key words: Echinococcus granulosus, CE, PAIR, pulmonary echinococcus.

\section{Introduction}

Echinococcosis is the general term used to describe four disease forms caused by the larval stage of Echinococcus tapeworms, the smallest tapeworms in the Taeniae family. Human echinococcosis is a zoonotic disease that occurs in four clinically well-described forms:

- Cystic echinococcosis (CE), also called hydatid disease or hydatidosis, is caused by infection with Echinococcus granulosus (E. granulosus).

- Alveolar echinococcosis (AE), also called alveolar hydatid echinococcosis is caused by infection with E. multilocularis.

- Polycystic echinococcosis is caused by infection with E. vogeli.

- Unicystic echinococcosis is caused by infection with E. oligarthrus.

$\mathrm{CE}$ and $\mathrm{AE}$ are the key forms of echinococcosis that

Corresponding author: Arturo L. Delgado, associate professor, MD, FCS, research field: paediatric surgery. are of significant medical and public health concerns for humans [1]. CE is caused by infection with the larvae of E. granulosus. CE is found worldwide and on every continent except Antarctica. Areas of the world with noted prevalence are rural regions of Africa, Southern Europe, Asia, the Middle East, Central and South America (especially the countries of Argentina and Uruguay). Cases are rare in North America. The parasite is transmitted to dogs when they eat organs of other animals that contain hydatid cysts. Once ingested by canines, these cysts develop into adult tapeworms. Infected dogs shed tapeworm eggs in their faeces, which contaminate the ground. Sheep, cattle, goats, and pigs ingest the E. granulosus eggs in the contaminated soil. Once eaten, the eggs hatch and develop into cysts in the animal's internal organs. CE is principally maintained in a dog-sheep-dog cycle, however other domestic animals may be involved, including goats, swine, horses, cattle, camels and yaks [1]. CE is regarded as endemic in sub-Saharan Africa; however, for most countries only scarce data, if any, 
exist. Available evidence suggests that several species or strains are prevalent in sub-Saharan Africa and that these strains might be associated with varying virulence and host preference. Treatment strategies (chemotherapy, percutaneous radiological techniques, but mainly surgery) predominantly target active disease. Prevention strategies encompass anthelmintic treatment of dogs, slaughter hygiene, surveillance, and health-educational measures. Existing data are suggestive of unusual clinical presentations of $\mathrm{CE}$ in some parts of the continent, for which the causes are speculative [2]. Hydatid cyst is a parasitic infection that grows faster in lung than in liver due to the elastic structure of lung. These cysts can be invasive to most part of the lobe by reaching giant dimensions. Hydatid cysts with a diameter of $10 \mathrm{~cm}$ or high are defined as giant hydatid cysts. Giant hydatid cysts are more common in childhood than adults [3-5]. Hydatid infestation of the lung can be primary or secondary. In three of four cases the cyst is a single one. Hydatidosis of a different location, particularly the liver, may be associated. The period of initial growth of primary hydatidosis is frequently asymptomatic. Bronchial fistulization is an important event in the evolution of the cyst. Intrapleural rupture constitutes a rare eventuality, but it is often as characteristic as it is severe. Secondary, metastatic hydatidosis, due to breaking of a primary visceral cyst in a vein or heart, is rare. There are a variety of radiographic images. Ultrasonography, computed tomography, and magnetic resonance imaging can recognize certain details of the lesions and discover others that are not visible by conventional radiography. A specific serologic diagnosis, favours the immunoglobulin G enzyme-linked immunosorbent assay and immunoelectrophoretic. Treatment is essentially surgical. In general, chemotherapy is used as a complement to operative treatment to avoid recurrence. Surgery has two objectives: to remove the parasite and to treat the bronchi peri cyst pathology and other associated lesions. The prognosis has changed during the last few years, and results are now commonly satisfactory. The most frequent complications are pleural infection and prolonged air leakage. Operative mortality does not exceed $1 \%$ to $2 \%$. Despite the low mortality and the limited recurrence rate, it is necessary to remember the invading character of pulmonary hydatid disease, which sometimes makes therapy difficult and questionable. Prophylaxis is essential to eradicate the disease completely $[6,7]$.

The objective of this study is to find out the prevalence and behaviour of lung hydatic cyst in children, in our region.

\section{Methods}

A retrospective study was done among children suffering from lung hydatic cyst admitted and treated in our Paediatric Surgery ward, from September 2015 to September 2017. Twelve children were studied, whose main clinical manifestation was cough, collected and analysed variables such as: age, sex, lung affected, unilateral or bilateral cyst, sizes of the cysts, treatment and complications. Imagenology was the method of diagnostic specially chest $\mathrm{X}$ ray and Computer tomography (CT). The treatment done was mostly surgical PAIR (punction, aspiration, injection and reaspiration plus removing the endocyst (germinal layer) and partial capitonnage on a drain tube, a conservative treatment with praziquantel and albendazole during 2-3 months, was given to patients with cysts size less than $6 \mathrm{~cm}$; this treatment was also given to every child after surgery. Were created several tables for its statistic study using the method of percent.

\section{Results}

In table 1 it shows, the age and gender presentations, noticing in $50 \%$ were in the age braked 6 to 10 years. The females accounted for 8 children (67\%). The female to male ration was $2: 1$.

The left lung was affected in 58\% of the case within group 6 to 10 years, however bilateral lung disease was seen in 3 cases, seen in Table 2. 
The pre-operative complications of the cysts are listed in Table 3. Broncho pleural fistulation was seen in 7 children (87.5\%), all of them in cysts greater than 6 $\mathrm{cm}$ in size. Rupture of the cyst in pleural space producing empyema occurred in one patient.

According to the data seen in Table 4 , in 8 cases $(67 \%)$ the treatment was surgical (PAIR + removal endocyst + capitonnage on a tube drain). Medical treatment (albendazol and praziquantel) was given to patients with cysts less than $6 \mathrm{~cm}$. The duration of the treatment was 2 to 3 months. This mode of treatment showed $92 \%$ total resolution of the cysts.

One case had rupture of the cyst into pleural space preoperatively resulting in an empyema. Moreover $87.5 \%$ developed bronco pleural fistulation as complication in Table 5.

Table 1 Age and gender presentation.

\begin{tabular}{|c|c|c|c|c|c|}
\hline Age vs. sex & Female & Male & Total & $\mathrm{N}$ & $\%$ \\
\hline $1-5$ years & 3 & & & 3 & 25 \\
\hline $6-10$ years & 3 & 3 & & 6 & 50 \\
\hline 10 years & 2 & 1 & & 3 & 25 \\
\hline Total & $8(67 \%)$ & 4 & & 12 & \\
\hline
\end{tabular}

Sources: clinical fields and author records.

Table 2 Age vs. lung affected.

\begin{tabular}{llllll}
\hline Lung & $1-5$ years & $6-10$ years & $>10$ years & Total: N & $\%$ \\
\hline Left & 1 & 6 & & 7 & 58 \\
Right & & 2 & 2 & 17 & 25 \\
Bilateral & 2 & 1 & 3 & \\
\hline
\end{tabular}

Sources: clinical fields and author records.

Table 3 Size of the cysts vs complications.

\begin{tabular}{lllll}
\hline Complications. & $<6 \mathrm{~cm}$ & $6-10 \mathrm{~cm}$ & $>10 \mathrm{~cm}$ & Total \\
\hline Bronchial communication & 6 & 1 & 7 & $87.5 \%$ \\
Rupture + empyema & & 1 & 1 & $67 \%$ \\
Total & $6(75 \%)$ & 2 & 8 & 6 \\
\hline
\end{tabular}

Sources: clinical fields and author records.

Table 4 Size of the cysts vs. type of treatment.

\begin{tabular}{llllll}
\hline Treatment & $<6 \mathrm{~cm}$ & $6-10 \mathrm{~cm}$ & $>10 \mathrm{~cm}$ & Total & $\%$ \\
\hline $\begin{array}{l}\text { Medical } \\
\text { (albendazole praziquantel) }\end{array}$ & 4 & & 4 & 33 \\
Surgical & & 6 & 2 & 8 & 67 \\
Cysts resolution (2-3 months) & 4 & 5 & 2 & 11 & 92 \\
\hline
\end{tabular}

Sources: clinical files and author records.

Table 5 Treatment and complications.

\begin{tabular}{|c|c|c|c|c|}
\hline Complications & Medical & Surgical & Total & $\%$ \\
\hline Rupture into pleural space & & 1 & 1 & \\
\hline Bronco pleural fistula (post op) & & 7 & 7 & 87.5 \\
\hline
\end{tabular}

Sources: clinical fields and author records. 


\section{Discussion}

This study showed the high incidence of lung hydatid disease in children older than 6 years $(75 \%)$. This finding was similar to Berrais et al. [8], where high incidence was in age group 4 to 18 years. Solak [3, $7,9]$ studied and showed higher incidence in male than female, this was not statistically significance. In our series females are more affected $[1,2]$.

In our study there was a predilection to the left lung $58 \%$ of the cases followed by bilateral hydatid cysts. This finding is dissimilar to other authors' finding [3]. Surgery was the prefer mode of treatment namely PAIR + removal of the endocyst layer and partial capitonnage on a drain tube. Conservative medical treatment with praziquantel and albensazole for two to three months was given to patients with cysts size less than $6 \mathrm{~cm}$ and post surgical intervention. None of the children on this study needed pulmonary resection as similar recommendation was advocated by Solak et al. [7] and Onal and Demir [3]. The commonest complication in our study was bronchial communication $87.5 \%$ and rupture in the pleural space resulting in empyema. Similar complication was reported by Omer et al. [3], Solak et al. [7], and Onal [3]. The resolution of the cysts occurred in $92 \%$ of the cases within two to three months after initiation of treatment (medical and surgical). There was not mortality in this study, similar finding was reported by Onal and Demir [3].

\section{Conclusions}

Through the analyzing of the clinical data of 12 children with lung echonococcosis we conclude:

(1) Lung hydatic cyst in our patients was observed more frequently in the left lung.
(2) The surgical treatment performed was PAIR mostly in cysts more than $6 \mathrm{~cm}$ or with complications.

(3) Conservative treatment is an option in some cases.

(4) Bronco pleural fistula as complication appeared in all patients after surgery.

(5) All fistulas closed spontaneously in 1-2 weeks.

\section{References}

[1] Defendi, G. L. 2015. Drugs \& Diseases. In "Pediatric Echinococcosis."

[2] Samad, E. J Golzari, Mohsen Sokouti, Alireza Ghaffari, Amir Mohammad Bazzazi, Kamya Ghabili. "Ultrasonography in Diagnosis of Pulmonary Hydatid Cysts.” The Lancet Infectious Diseases 13 (4): 294.

[3] Onal, O., and Demir, O. F. 2017. "Is Anatomic Lung Resection Necessary in Surgical Treatment of Giant Lung Hydatid Cysts in Childhood?" Ann Thorac Cardiovasc Surg. 23 (6): 286-90.

[4] Karaoglanoglu, N., Kurkcuoglu, I. C., Gorguner, M., et al. 2001. "Giant Hydatid Lung Cysts." Eur J Cardiothorac Surg 19: 914-7.

[5] Halezeroglu, S., Celik, M., Uysal, A., et al. 1997. "Giant Hydatid Cysts of the Lung." J Thorac Cardiovasc Surg 113: 712-7.

[6] Ramos, G., Orduña, A., and García-Yuste, M. 2001. "Hydatid Cyst of the Lung: Diagnosis and Treatment." World J Surg. 25 (1): 46-57.

[7] Solak, H., Yeniterzi, M., Yüksek, T., Anil, N., Göktoğan, T., and Ceran, S. 1990. "The Hydatid Cyst of the Lung in Children and Results of Surgical Treatment." Thorac Cardiovasc Surg. 38 (1): 45-7.

[8] Berraies, A., Moussa, C., Hamdi, B., Aqqad, A., Louhaichi, S., Ammar, J., Kilani, T., and Hamzaoui, A. 2015. "Characteristics and Outcomes of Pulmonary Hydatid Disease in Children: About 70 Cases." European Respiratory Journal doi 10.1183/13993003.congress-2015.PA3631.

[9] Kanat, F., Turk, E., and Aribas, O. K. 2004. "Comparison of Pulmonary Hydatid Cysts in Children and Adults." ANZ J Surg. 74 (10): 885-9. 